Gut, 1979, 20, 629-633

\title{
Rôle of calcitonin in diarrhoea associated with medullary carcinoma of the thyroid
}

\author{
T. M. COX, ElizABETH A. FAGAN, CARMEL J. HillyaRd, D. J. Allison, \\ AND V. S. CHADWICK \\ From the Departments of Gastroenterology, Radiology, and Endocrinology, Royal Postgraduate Medical \\ School, Hammersmith Hospital, London
}

SUMMARY Severe watery diarrhoea in a patient with medullary thyroid carcinoma and high calcitonin levels was associated with increased distal ileal flow. Plasma from the patient inhibited small intestinal fluid absorption in dogs without affecting mucosal cyclic AMP levels. When calcitonin was removed from the plasma, the effect in experimental bowel loops was abolished but could be restored on restitution of comparable hormone levels with pure calcitonin. These studies, combined with the failure to find evidence of increased prostaglandin activity in the patient, suggest that circulating calcitonin may be a major cause of the diarrhoea in medullary thyroid carcinoma.

Watery diarrhoea in medullary carcinoma of the thyroid occurs in up to $30 \%$ of cases and may respond to removal of tumour tissue (Williams, 1966; Bernier et al., 1969). Previous clinical studies have shown abnormalities of small bowel motility and fluid and electrolyte absorption (Bernier et al., 1969; Isaacs et al., 1974).

Among the substances elaborated by the tumour which could cause diarrhoea, prostaglandins and calcitonin are suggested causative agents. Raised blood and tumour prostaglandins have been found in some patients, and prostaglandins can produce diarrhoea in man and experimental animals (Williams et al., 1968; Cummings et al., 1973). Prostaglandins activate the adenyl cyclase/cAMP mechanism, leading to net intestinal fluid secretion. In contrast, calcitonin is invariably raised in medullary carcinoma (Melvin et al., 1972). It is also a potent secretagogue in both human and rabbit small intestine (Kisloff and Moore, 1977; Gray et al., 1975), but its mechanism of action is unknown.

In order to determine the mechanism of diarrhoea in a patient suffering from this tumour, we first measured plasma levels of hormones known to alter intestinal fluid transport. Secondly, distal ileal flow was monitored, as an index of net fluid absorption in the small intestine. The cyclic AMP levels in the patients' small bowel mucosa were also measured. Finally, the diarrhoeagenic factor in the patient's plasma was studied by bioassay in the dog small intestine.

Received for publication 7 February 1979

\section{Case history}

N.M., a 58 year old secretary, presented in January 1977 with a seven month history of profuse watery diarrhoea: $600-1300 \mathrm{~g}$ of semi-liquid stool was passed daily in spite of medication with antimotility drugs. Clinical examination was normal and no goitre was found. Routine haematological measurements and serum electrolytes were normal apart from hypokalaemia 3.1-3.4 $\mathrm{mmol} / 1$. Stool electrolyte analysis showed potassium $64 \mathrm{mmol} / \mathrm{l}$; chloride $18 \mathrm{mmol} / 1$; sodium $65 \mathrm{mmol} / 1$; magnesium $2.4 \mathrm{mmol} / \mathrm{l}$. On a standard $70 \mathrm{~g}$ fat diet $6.9 \mathrm{~g}$ of fat was excreted in the stools daily. Absorption of oral vitamin B12 given with intrinsic factor, as well as an oral glucose load were normal. Urinary 5-hydroxy indole acetic acid outputs were normal on two occasions at 23 and $25 \mu \mathrm{mol} / 24 \mathrm{~h}$. The only abnormality detected on barium studies was rapid transit of contrast through the small intestine. Jejunal biopsy was histologically normal. Biopsy of lytic skull lesions, which were found incidentally on radiological survey, showed necrotic metastatic medullary thyroid carcinoma, and a single primary nodule of medullary carcinoma was later found at thyroidectomy. Typical calcitonin granules were seen on electron microscopy and immunofluorescence for calcitonin was positive (Dr J. Polak, Hammersmith Hospital).

Severe secretory diarrhoea persisted in spite of fasting and, together with hypokalaemia, prompted therapeutic trials of prostaglandin inhibitors, indomethacin and nutmeg, as well as inhibitors of 
cAMP, nicotinic acid and colchicine. Neither oral indomethacin $800 \mathrm{mg} /$ day, nutmeg $12 \mathrm{~g} /$ day, nicotinic acid, $3.6 \mathrm{~g} /$ day, nor colchicine $1.5 \mathrm{mg} /$ day reduced the diarrhoea. The patient subsequently developed severe leucoerythroblastic anaemia and died in September 1978 as a result of inanition and metastatic bone disease, complicated by pathological fracture of the femur and sepsis. Thyroidectomy did not affect the diarrhoea, and there had been little objective response to cytotoxic treatment given over a period of nine months.

\section{Methods}

The following methods were used in studying the mechanism of diarrhoea.

\section{MEASUREMENT OF LEVELS OF ACTIVE \\ PRINCIPLES IN PLASMA}

Fasting plasma was taken for radioimmunoassay of calcitonin (Hillyard et al., 1977), gastrin, and vasoactive intestinal polypeptide (Bloom et al., 1973). Plasma prostaglandin levels were measured in the rat gastric fundus bioassay by $\operatorname{Dr} \mathrm{A}$. Bennett of King's College Hospital, London (Unger et al., 1971).

DISTAL ILEAL FLOW

Daily distal ileal flow was measured by the slow marker perfusion technique of Phillips and Giller (1973). PEG 4000 was used as a non-absorbable marker. The patient and four healthy control subjects were allowed normal meals during the 24 hour test period from $6 \mathrm{am}$. PEG in the aspirates was determined by the method of Hydèn (1956).

\footnotetext{
ASSAY OF MUCOSAL CAMP IN SMALL

INTESTINAL BIOPSIES

Mucosal biopsies were taken with the Crosby capsule from the proximal jejunum in the patient and from 11 control subjects. These control patients had complained of non-specific abdominal symptoms and were found to have histologically normal mucosa. The tissue was immediately incubated at $90^{\circ} \mathrm{C}$ for five minutes to inactivate phosphodiesterase before storage at $-40^{\circ} \mathrm{C}$ before homogenisation and assay. CAMP was determined by the competitive protein binding method described by Gilman (1970) using $\left[{ }^{3} \mathrm{H}\right]$-cAMP (Amersham Radiochemicals Ltd, Amersham, England) and protein kinase prepared from rabbit gastrocnemius. Mucosal protein was measured by the method of Lowry et al. (1951), using crystalline bovine serum albumin in standards.
}

BIOASSAY OF PATIENT'S PLASMA IN DOG

SMALL INTESTINE

Four greyhound dogs $(20-25 \mathrm{~kg})$ were anaesthetised with Nembutal, and a steerable catheter was introduced into the ostium of the superior mesenteric artery via the femoral artery under fluroscopic control. Urinary output was monitored by means of a bladder catheter. Through a midline abdominal incision, $30 \mathrm{~cm}$ segments of jejunum and ileum were isolated between balloon catheters and perfused with a solution of PEG $4000,5 \mathrm{~g} / 1$ in $0 \cdot 12 \mathrm{M} \mathrm{NaCl}$ at a rate of $5 \mathrm{ml}$ per minute. After an initial 30-40 minute equilibration period, samples of effluent were collected at five minute intervals for PEG determination. Pooled human control plasma was infused at a rate of $2-3 \mathrm{ml}$ per minute into the superior mesenteric artery for approximately one hour, followed by infusion of the patient's plasma, obtained by plasmapheresis (and containing 280$350 \mu \mathrm{g}$ calcitonin/l) for a further hour. Fluid absorption was measured during the last 20 minutes of each infusion, when a new steady state was achieved. At the end of the experiment, the distribution of the blood supply to the small intestine was determined by injection of radio-opaque contrast material via the arterial catheter. Mucosal biopsies from bowel adjacent to the test loops were obtained during control and test periods; they were prepared immediately for cAMP analysis (as described above). For sequential infusions, during which samples of perfusate were collected at 10 minute intervals, the patient's plasma was stripped of calcitonin by double extraction with Spherosil beads (Hillyard et al., 1977) and restored after adsorption to $\mathrm{pH} \mathrm{7 \cdot 4}$. For the restitution of calcitonin levels in the adsorbed plasma, pure synthetic human calcitonin was used-Ciba C47 $175 \mathrm{Ba}$. After adsorption, immunoreactive calcitonin was virtually undetectable at $0.12 \mu \mathrm{g} / \mathrm{l}$ in the patient's plasma.

\section{Results}

\section{HORMONE LEVELS}

Random fasting calcitonin levels were grossly raised on 20 occasions and ranged from 20.2 to $680 \mu \mathrm{g} / 1$ (normal less than $0.08 \mu \mathrm{g} / \mathrm{l}$ ). Daily variations between 350 and $650 \mu \mathrm{g} / 1$ were recorded. Plasmapheresis did not reduce the patients' diarrhoea but, after the procedure, calcitonin levels in excess of $100 \mu \mathrm{g} / 1$ were recorded. Plasma gastrin levels of $36 \mathrm{pmol} / 1$ and VIP, 9 and $14 \mathrm{pmol} / 1$ were within the normal limits of less than $50 \mathrm{pmol} / 1$. Plasma prostaglandin levels of $0.12 \mathrm{ng}$ equivalents $\mathrm{PGE}_{2} / \mathrm{ml}$ were found in femoral vein plasma. Simultaneously, 0.10 and $0.11 \mathrm{ng}$ equivalents $/ \mathrm{ml}$ were found in normal thyroid vein and a tumour draining vein, 
lents $/ \mathrm{ml}$ have been found in normal individuals. than $0.3 \mathrm{ng} / \mathrm{ml}$, although levels up to $2.5 \mathrm{ng}$ equivaglandins from the tumour; values are usually less respectively. These indicate no release of prosta-

\section{ILEAL FLOW}

Daily distal ileal flow in the patient compared with the range in the normal control subjects is shown in Fig. 1. Net total ileal flow was 3.51 per day in the patient compared with the controls $2.34 \pm 0.6 \mathrm{SD}$; range 1.67-2.90 1 per day. The increased flow was particularly evident after meals, but its relationship to calcitonin levels throughout the period was not studied.

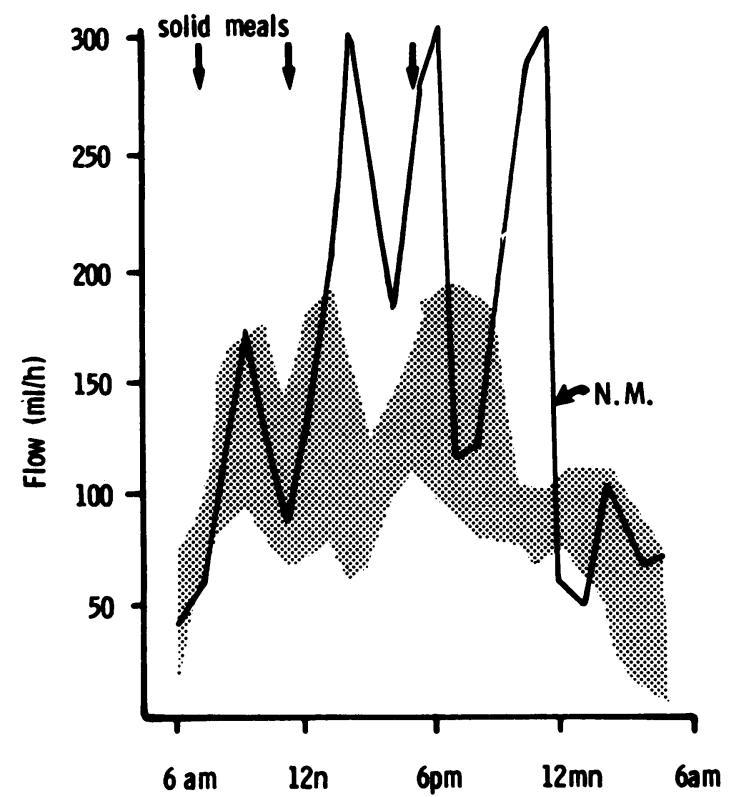

Fig. 1 Distal ileal flow in the patient (N.M.) and the range for four healthy control subjects as measured by the slow marker perfusion technique (see text).

CYCLIC AMP IN JEJUNAL MUCOSA

The mucosal cAMP level in the patient was 1.9 $\mathrm{pmol} / \mathrm{mg}$ protein. This was lower than the mean value of $7.9 \pm 0.74 \mathrm{SEM} \mathrm{pmol} / \mathrm{mg}$ protein for the 11 control subjects, who were subsequently not found to have organic digestive disease.

EFFECTS OF THE PATIENT'S PLASMA IN EXPERIMENTAL BOWEL LOOPS

When compared with control plasma infusions, the patient's plasma inhibited net total fluid absorption in the perfused dog intestinal loops (Table). Although there were individual variations in the degree of response, the major effect was seen in the jejunum, where there was a threefold reduction of fluid transport. A smaller reduction also occurred in the ileum. The inhibition of fluid absorption in the loops is significant at $P<0.05$ by the one-tail Wilcoxon pair differences test. The mean fall was $14 \cdot 8$ $\mathrm{ml} / 30 \mathrm{~cm}$ loop/h (range 5.2-36.9). The ability of the intestine to absorb consistently in a second control period is shown by studies in an animal infused with control plasma over a third hour: mean absorption over the first infusion period was $24.4 \mathrm{ml} / 30 \mathrm{~cm}$ loop/h but fell to $14.7 \mathrm{ml} / \mathrm{loop} / \mathrm{h}$ during the test infusion; over the final control infusion, absorption was restored to $22 \cdot 1 \mathrm{ml} / \mathrm{loop} / \mathrm{h}$.

Table Effect of plasma on fluid absorption in dog small intestine $(\mathrm{ml} / 30 \mathrm{~cm}$ loop/h)

\begin{tabular}{|c|c|c|c|}
\hline \multirow[t]{2}{*}{ Experiment } & \multicolumn{3}{|l|}{ Infusate } \\
\hline & Control plasma & Patient's plasma & $\begin{array}{c}\text { Inhibition } \\
\%\end{array}$ \\
\hline 1 Jejunum & $15 \cdot 6$ & $\begin{array}{l}10.3 \\
15.0\end{array}$ & 33 \\
\hline $\begin{array}{l}\text { Ileum } \\
\text { Jejunum }\end{array}$ & $\begin{array}{l}22 \cdot 3 \\
70 \cdot 8\end{array}$ & $\begin{array}{c}15 \cdot 0 \\
-0.3^{*}\end{array}$ & נכ \\
\hline 2 Ileum & $27 \cdot 3$ & 25.0 & 75 \\
\hline Jejunum & $12 \cdot 3$ & $13 \cdot 8$ & \\
\hline 3 Ileum & 4.9 & $-18 \cdot 4^{*}$ & $* 127$ \\
\hline $4 \begin{array}{l}\text { Jejunum } \\
\text { Ileum }\end{array}$ & $\begin{array}{l}28 \cdot 7 \\
10 \cdot 6\end{array}$ & $\begin{array}{l}11.9 \\
17.0\end{array}$ & 29 \\
\hline Mean \pm SEM & $24 \cdot 1 \pm 7 \cdot 3$ & $9 \cdot 3 \pm 4.7$ & 66 \\
\hline
\end{tabular}

*Net secretion.

The results of a sequential study in the jejunum of one animal are shown in Fig. 2. In this experiment, control plasma, patient's plasma, and stripped patient's plasma were infused. Finally, adsorbed plasma, to which pure human calcitonin had been added to $350 \mu \mathrm{g} / 1$, was infused.

The infusion of the patient's plasma promptly inhibited fluid absorption in the loops and, after 50 minutes, a net secretion of $12 \mathrm{ml} / 30 \mathrm{~cm}$ loop/h was induced. This effect was rapidly abolished by infusion of the adsorbed plasma, only to be restored to net secretion when pure calcitonin had been added to the inactivated plasma.

Cyclic AMP levels in jejunal and ileal mucosa in the experimental loops of all the animals were respectively $4.5 \pm 2.3$ and $11.9 \pm 4.8$ (SEM) $\mathrm{pmol} / \mathrm{mg}$ protein during infusion of control plasma, and $4.0 \pm 2.1$ and $12.4 \pm 6.0 \mathrm{pmol} / \mathrm{mg}$ protein during infusion of the patient's plasma. These results are not significantly different.

\section{Discussion}

The present findings suggest that a humoral factor, calcitonin, was the cause of diarrhoea in our patient. Calcitonin levels were markedly raised, whereas other hormones known to affect small bowel fluid trans- 


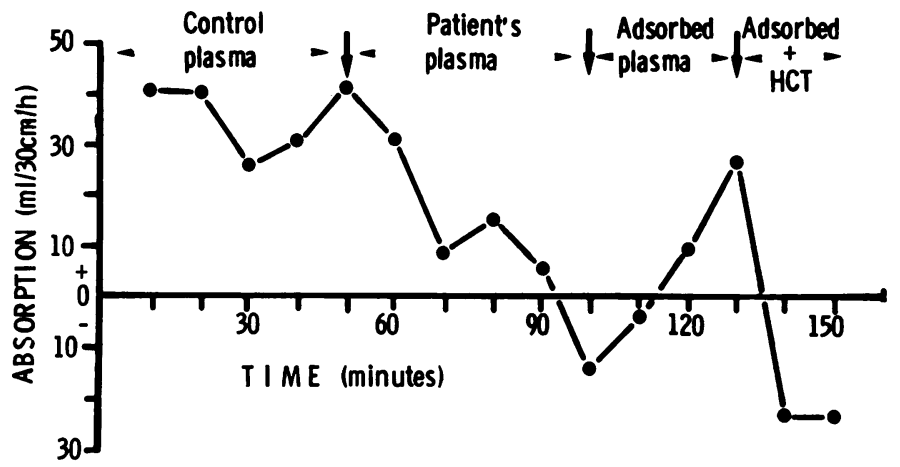

Fig. 2 Effect of serial plasma infusions on fluid absorption in the perfused dog jejunum. Positive values on the vertical axis represent net fluid absorption; negative values represent net fluid secretion.

port were normal. When the patient's plasma was stripped of calcitonin, its secretory effect in dog intestine was abolished. Furthermore, restitution of comparable levels with pure hormone restored experimental secretory activity to the inactivated plasma. Insufficient calcitonin was available for studies with the hormone alone or with control plasma, and it remains possible that calcitonin and another tumour principle act synergistically to cause diarrhoea.

Other workers (Williams et al., 1968) have implicated prostaglandins as the diarrhoeagenic agents in this condition. Our case resembles that of Isaacs et al. (1974): increased prostaglandin bioactivity was not demonstrated and trials of prostaglandin inhibitors failed to affect the diarrhoea. Since prostaglandins stimulate adenyl cyclase (Kimberg et al., 1971), the absence of increased cAMP levels in the patient's biopsy or in the dog intestine during bioassay of the patient's plasma is further evidence against prostaglandin mediation. In fact, the level of cAMP in the patient's mucosa was below our two standard deviation normal range, though the reason for this is not clear.

Abnormalities of small intestinal fluid absorption as well as motility have been previously reported in patients with medullary carcinoma of the thyroid (Bernier et al., 1969; Isaacs et al., 1974). Distal ileal flow was markedly increased in our patient, and the patient's plasma inhibited fluid absorption experimentally in the dog small intestine. Studies of colonic fluid transport have not been reported in this condition and, although the magnitude of the increase in distal ileal flow is sufficient to account for the increased daily stool volume (Phillips and Giller, 1973), additional effects on the colon are possible.

Only $30 \%$ of patients with medullary carcinoma develop diarrhoea, although plasma calcitonin is invariably raised (Melvin et al., 1972). However, experimental infusions of heterologous calcitonin in man have a consistent effect on small intestinal fluid and electrolyte absorption (Gray et al., 1975). Tumour-elaborated calcitonin may have variable bioactivity or be released intermittently, so that diarrhoea does not result. Alternatively, compensatory colonic absorption could mask the effect in some patients, since, as Evans (1977) has pointed out, less than $12 \%$ of patients given fixed doses of human calcitonin for the treatment of Paget's disease develop diarrhoea.

Selective removal of calcitonin from plasma requires affinity chromatography. This was not possible in our study because enormous quantities of pure anti-human calcitonin antibody would have been required to strip a large volume of plasma. The technique we used removes calcitonin with high efficiency, but it remains possible that other diarrhoeagenic factors might be removed at the same time. However, restoration of comparable levels of pure human calcitonin in the stripped plasma also restored bioactivity.

The mechanism of action of calcitonin on intestinal fluid handling is obscure, but our findings concur with the observations of Schwartz et al. (1974) and Walling et al. (1977), who found no activation of adenyl cyclase or cyclic nucleotides in preparations of rodent small bowel mucosa induced to secrete by in vitro incubation with the hormone. An action on $\mathrm{Na} / \mathrm{K}$ ATPase or the sensitivity of protein kinases remains to be investigated.

We thank Professor D. K. Peters and Dr C. M. Lockwood for enabling us to obtain plasma by plasmapheresis. We are indebted to Dr A. Bennett for the prostaglandin estimation, and to Dr M. T. MacMahon for referring the patient. Finally, we should like to thank Miss Sue Rump and Miss Hilary Stanbrook for expert technical assistance and Miss Berny Murphy for typing the manuscript. Ciba C47 175B was kindly supplied by Ciba Geigy Ltd. 


\section{References}

Bernier, J. J., Rambaud, J. C., Cattan, D., and Prost, A. (1969). Diarrhoea associated with medullary carcinoma of the thyroid. Gut, 10, 980-985.

Bloom, S. R., Polak, J. M., and Pearse, A. G. E. (1973). Vasoactive intestinal peptide and watery-diarrhoea syndrome. Lancet, 2, 14-16.

Cummings, J. H., Newman, A., Misiewicz, J. J., MiltonThompson, G. J., and Billings, J. A. (1973). Effect of intravenous prostaglandin $F_{2}$ on small intestinal function in man. Nature, 243, 169-171.

Evans, I. M. A. (1977). Human calcitonin in the treatment of Paget's disease: long-term trials. In Human Calcitonin and Paget's Disease, pp. 111-123. Edited by I. MacIntyre. Huber: Berne.

Gilman, A. G. (1970). A protein binding assay for adenosine $3^{\prime}$ : 5'-cyclic monophosphate. Proceedings of the National Academy of Sciences of the United States of America, 67, 305-312.

Gray, T. K., Bieberdorf, F. A., and Fordtran, J. S. (1975). Thyrocalcitonin and the jejunal absorption of calcium, water, and electrolytes in normal subjects. Journal of Clinical Investigation, 52, 3084-3088.

Hillyard, C. J., Cooke, T. J. C., Coombes, R. C., Evans, I. M. A., and MacIntyre, I. (1977). Normal plasma calcitonin: circadian variation and response to stimuli. Clinical Endocrinology, 6, 291-298.

Hydèn, S. (1956). A turbidimetric method for the determination of higher polyethylene glycols in biological materials. Kungliga Lantbrukshögskolans Annaler, 22, 139-145.

Issacs, P., Whittaker, S. M., and Turnberg, L. A. (1974). Diarrhoea associated with medullary carcinoma of the thyroid. Gastroenterology, 67, 521-526.
Kimberg, D. V., Field, M., Johnson, J., Henderson, A., and Gershon, E. (1971). Stimulation of intestinal mucosal adenyl cyclase by cholera enterotoxin and prostaglandins. Journal of Clinical Investigation, 50, 1218-1230.

Kisloff, B., and Moore, E. W. (1977). Effects of intravenous calcitonin on water, electrolyte, and calcium movement across in vivo rabbit jejunum and ileum. Gastroenterology, $72,462-468$.

Lowry, O. H., Rosebrough, N. J., Farr, A. L., and Randall, R. J. (1951). Protein measurement with the Folin phenol reagent. Journal of Biological Chemistry, 193, 265-275.

Melvin, K. E. W., Tashjian, A. H., Jnr, and Miller, H. H. (1972). Studies in familial (medullary) thyroid carcinoma. Recent Progress in Hormone Research, 28, 399-470.

Phillips, S. F., and Giller, J. (1973). The contribution of the colon to electrolyte and water conservation in man. Journal of Laboratory and Clinical Medicine, 81, 733-746.

Schwartz, C. J., Kimberg, D. V., Sheerin, H. E., Field, M., and Said, S. I. (1974). Vasoactive intestinal peptide stimulation of adenylate cyclase and active electrolyte secretion in intestinal mucosa. Journal of Clinical Investigation, 54, 536-544.

Unger, W. G., Stamford, I. F., and Bennett, A. (1971). Extraction of prostaglandins from human blood. Nature, 233, 336-337.

Walling, M. W., Brasitus, T. A., and Kimberg, D. V. (1977). Effects of calcitonin and substance $P$ on the transport of $\mathrm{Ca}, \mathrm{Na}$, and $\mathrm{Cl}$ across rat ileum in vitro. Gastroenterology, 73, 89-94.

Williams, E. D. (1966). Diarrhoea and thyroid carcinoma. Proceedings of the Royal Soicety of Medicine, 59, 602-603.

Williams, E. D., Karim, S. M. M., and Sandler, M. (1968). Prostaglandin secretion by medullary carcinoma of the thyroid. Lancet, 1, 22-23. 